\title{
A Review on Performance of Air Conditioning System using Two Phase Ejector
}

\author{
Harish Choudhary" ${ }^{*}$, B.S.Kothavale ${ }^{\#}$ and K.V.Mali\# \\ \#Department of Mechanical Engineering, MIT College of Engineering, Savitribai Phule Pune University, India \\ Accepted 03 March 2016, Available online 15 March 2016, Special Issue-4 (March 2016)
}

\begin{abstract}
This paper presents a useful knowledge of ejector working principles and its applications in refrigeration technologies. Two-phase flow ejector is used as an expansion device in vapour compression refrigeration systems is one of the efficient ways to enhance its performance. The expansion process (isenthalpic process) represents one of the most important sources of irreversibility in the conventional vapour compression refrigeration systems. Use of a two-phase flow ejector instead of the conventional expansion device is one of the efficient techniques to improve the system performance not only by recover the expansion process loss by generating isentropic expansion process but also by increase the system cooling capacity and decrease the compressor power. Most recent investigations have been concentrated on transcritical ejector-expansion refrigeration cycles (EECS) because of the large improvement potential owing to the high throttling loss. Subcritical EECs have received much less attention because these cycles offer relatively lower improvement potential through the ejector action.
\end{abstract}

Keywords: Vapour compression refrigeration systems, two phase flow ejector.

\section{Introduction}

Refrigeration is one of the leading uses of electric power across the globe. The term refrigeration refers to air-conditioning for homes, businesses, and industry and the operation of refrigerators, freezers, and heat pumps. The technology mostly in use today for refrigeration purpose is the vapour compression cycle which is 100 years old, inefficient, and environmentally unsound. The refrigeration industry has faced pressure to improve efficiency and reduce the emission of the chlorofluorocarbons (CFC) compounds which pose a serious threat to the environment. Hence attempts are made to decrease CFC emissions by using alternate compounds which had typically made refrigeration devices less efficient.

Ideally, the pressure drop in refrigeration cycle is considered as an isenthalpic process where the enthalpy remains constant. However, isenthalpic process causes a reduction in the evaporator cooling capacity due to energy loss in the throttling process. An efficiency-enhancing alternative was proposed to recover this energy loss, which uses an ejector that can be used to generate isentropic condition where ideally the entropy remains constant in the throttling process. Such a cycle is called as ejector expansion refrigeration cycle. The ejector expansion refrigeration cycle is

*Corresponding author: Harish Choudhary different from the standard vapour compression cycle in which an ejector is used to recover part of the work that would otherwise be lost in the expansion valve.

This method uses a two-phase ejector as an expansion device while the conventional refrigeration cycle uses an expansion valve. A typical ejector consists of a motive nozzle, a suction nozzle or receiving chamber, a mixing section and a diffuser. High pressure motive stream expands in the motive nozzle and its internal energy converts to kinetic energy. The high speed motive stream entrains low pressure suction stream into the mixing section. These both streams exchange momentum, kinetic and internal energies in the mixing section and become one stream with almost uniform pressure and speed. The stream converts its kinetic energy into internal energy in the diffuser to reach a pressure higher than the suction stream inlet pressure.

\subsection{Difference between Conventional and Ejector Systems}

1) The conventional air-conditioning systems use a compressor for mechanical compression. In case of ejector systems, the compression is done by the ejector, thus eliminating the need of compressor.

2) The main difference between ejector cycle and the conventional refrigeration cycle (reverse Rankine cycle), besides elimination of a compressor, is that 
it requires three heat sources at different temperatures rather than two, namely at the generator level, which is the temperature of the solar waste heat source, at a condensing level, which is the ambient temperature (actually this is a heat sink) and the evaporator temperature required for cooling effect.

\subsection{Various Applications of Ejectors}

There are a number of applications in refrigeration and air-conditioning where ejectors can be used to help improve the overall performance of the system. Some of them are listed below.

1) Ejector for utilizing of low-grade energy.

2) Ejector for recovery of expansion work.

3) Ejector for driving liquid recirculation through the evaporator using expansion work.

4) Ejector for increasing the compressor discharge pressure.

\section{Literature Survey}

Most recent investigations have been concentrated on transcritical R744 ejector-expansion refrigeration cycles (EECs) because of the large improvement potential owing to the high throttling loss. Subcritical EECs have received much less attention because these cycles offer relatively lower improvement potential through the ejector action. However, it is still worth investigating these subcritical cycles with a two-phase ejector to improve the cycle performance.

Nehdi et al. numerically discovered that replacing the throttle valve with a two-phase ejector improved COP up to $22 \%$ in a vapour compression system using $\mathrm{R} 141 \mathrm{~b}$ as refrigerant. Bilir and Ersoy found theoretically that an EEC using R134a could provide $22.3 \%$ COP improvement compared with that of basic cycle. It also experimentally found that the use of an ejector in place of the throttle valve in a R134a refrigeration cycle will improve the COP and exergy efficiency by $7.34 \%-12.87 \%$ and $6.6 \%-11.24 \%$, respectively, under the same external operating conditions.

Disawas and Wongwises presented experimental results comparing an EEC to the basic cycle using $\mathrm{R} 134 \mathrm{a}$ as the refrigerant. In their cycle, there was no throttle valve upstream of the evaporator so that the evaporator is flooded with the refrigerant. The COP improvement of about 5\% was obtained. The effects of size of the motive nozzle outlet on the system performance were discussed by Chaiwongsa and Wongwises. They found that motive nozzles with different outlet diameters in the range of $2.0-3.0 \mathrm{~mm}$ yielded insignificant effects on the system performance.
Pottker and Hrnjak experimentally tested an R410A EEC and reported improvements from $8.2 \%$ to $14.8 \%$ over the basic system. Lawrence and Elbel conducted an experimental investigation of EEC that can provide multiple evaporation temperatures, and found that the cycle showed maximum COP improvements of $12 \%$ with R1234yf and 8\% with R134a compared with a two evaporation temperatures basic cycle. However, the cycle showed maximum COP improvements of only $6 \%$ with R1234yf and 5\% with R134a compared with a single evaporation temperature basic cycle.

Table No. 1 The summary of numerical works on the Standard ejector systems

\begin{tabular}{|c|c|c|c|}
\hline Authors & Year & $\mathrm{COP}_{\mathrm{imp}}$ & Working fluid \\
\hline Kornhauser & 1990 & $21 \%$ & $\begin{array}{c}\text { R11, R12, R22, } \\
\text { R113, R114, } \\
\text { R500, R502, } \\
\text { R717 }\end{array}$ \\
\hline Liu et al. & 2002 & $\begin{array}{l}11.9- \\
21.6 \%\end{array}$ & $\begin{array}{l}\text { R717, R290, } \\
\text { R600a }\end{array}$ \\
\hline Li and Groll & 2005 & $16 \%$ & $\mathrm{CO}_{2}$ \\
\hline Nehdi et al. & 2007 & $22 \%$ & \pm 20 refrigerants \\
\hline Deng et al. & 2007 & $22 \%$ & $\mathrm{CO}_{2}$ \\
\hline $\begin{array}{c}\text { Yari \& } \\
\text { Sirousazar }\end{array}$ & 2008 & $55.5 \%$ & $\mathrm{CO}_{2}$ \\
\hline Bilir and Ersoy & 2009 & $\begin{array}{c}10.1- \\
22.34 \%\end{array}$ & R134a \\
\hline Sarkar & 2010 & $\begin{array}{l}11.9- \\
21.6 \%\end{array}$ & $\begin{array}{l}\text { R290, R600a, } \\
\text { R717 }\end{array}$ \\
\hline $\begin{array}{l}\text { Banasiak \& } \\
\text { Hafner }\end{array}$ & 2011 & - & $\mathrm{CO}_{2}$ \\
\hline Sumeru et al. & 2013 & $\begin{array}{c}1.99- \\
23.03 \%\end{array}$ & R22 \\
\hline
\end{tabular}

There are a lot of difficulties in the two-phase ejector research due to the complex flow; however, more and more researchers focus on this field due to the potential of energy recovery in the refrigerating system. By studying the nozzle diameter and the diffuser angle, it was found that a properly designed ejector can increase the system COP over $14.5 \%$.

With the development of computational fluid dynamics, a large number of CFD models have been published which deal with multi-dimensional, multiphase flow problems. Some of the ejector calculation solvers are based on the Navier Stokes equation in 2D and 3D. In this way the ejector performance can be predicted, but these multi-purpose CFD codes and software's still could not deal specifically with two-phase ejector flow possibly due to the model limitations. Therefore the prediction accuracy is limited. Because of the model limitations, experiment was the best method to predict the ejector performance. 
Table No. 2 The summary of experimental works on the standard ejector systems

\begin{tabular}{|c|c|c|c|}
\hline Authors & year & CoP & $\begin{array}{c}\text { Working } \\
\text { fluid }\end{array}$ \\
\hline $\begin{array}{c}\text { Harrell and } \\
\text { Kornhauser }\end{array}$ & 1995 & $3.9-7.6 \%$ & $\mathrm{R} 134 \mathrm{a}$ \\
\hline $\begin{array}{c}\text { Menegay and } \\
\text { Kornhauser }\end{array}$ & 1996 & $3.2-3.8 \%$ & $\mathrm{R} 12$ \\
\hline $\begin{array}{c}\text { Disawas and } \\
\text { Wongwises }\end{array}$ & 2004 & $\begin{array}{c}\text { Higher than } \\
\text { standard cycle }\end{array}$ & $\mathrm{R} 143 \mathrm{a}$ \\
\hline Ozaki et al. & 2004 & $20 \%$ & $\mathrm{CO}_{2}$ \\
\hline $\begin{array}{c}\text { Wongwises and } \\
\text { Disawas }\end{array}$ & 2005 & $\begin{array}{c}\text { Higher than } \\
\text { standard cycle }\end{array}$ & $\mathrm{R} 134 \mathrm{a}$ \\
\hline Deng et al. & 2007 & $22 \%$ & $\mathrm{CO}_{2}$ \\
\hline $\begin{array}{c}\text { Chaiwongsa } \\
\text { and Wongwises }\end{array}$ & 2007 & $\begin{array}{c}\text { Higher than } \\
\text { standard cycle }\end{array}$ & $\mathrm{R} 134 \mathrm{a}$ \\
\hline $\begin{array}{c}\text { Elbel and } \\
\text { Hrnjak }\end{array}$ & 2008 & $7 \%$ & $\mathrm{CO}_{2}$ \\
\hline Elbel & 2011 & $7 \%$ & $\mathrm{CO}_{2}$ \\
\hline $\begin{array}{c}\text { Lucas and } \\
\text { Koehler }\end{array}$ & 2012 & $17 \%$ & $\mathrm{CO}_{2}$ \\
\hline
\end{tabular}

The majority of available literature concerned with ejectors used in refrigeration describes numerical simulations. A number of established ejector flow theories and experiments point out the importance of flow choking and shock wave phenomena.

\section{General Ejector working principles}

\subsection{Ejector working processes}

An ejector, also named as injector, jet pump, thermocompressor, is a flow device that allows a high pressure primary fluid to accelerate and induce a low pressure secondary fluid into the primary fluid path. As the two fluids mix through a diffuser section, a pressure recovery occurs, which enables the ejector to fulfil the function of a compressor or a pump. The term primary is defined as the driving, motive, or energizing flow for the ejector, while the term secondary means the driven, passive, or energized flow.

The ejector has a simple structure of four parts: a nozzle, a suction chamber, a mixing chamber and a diffuser, as illustrated in figure 1 The flow phenomena inside the ejector are quite complicated and the detailed flow mechanism is not yet quite clear as supersonic flow, shock interactions, turbulent mixing and two-phase flow may involve. The flow patterns inside an ejector may be visualized and analyzed by using optical instruments and computational fluid dynamics (CFD). The main geometry is characterized by the area ratio $A_{r}$, which is defined as the area of the constant-area part in the mixing chamber divided by the nozzle throat area, i.e. $\left(D_{m} / D_{t}\right)^{2}$.

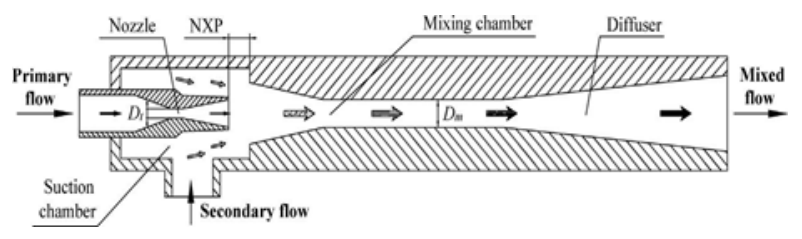

Fig.1 Schematic drawing of the ejector

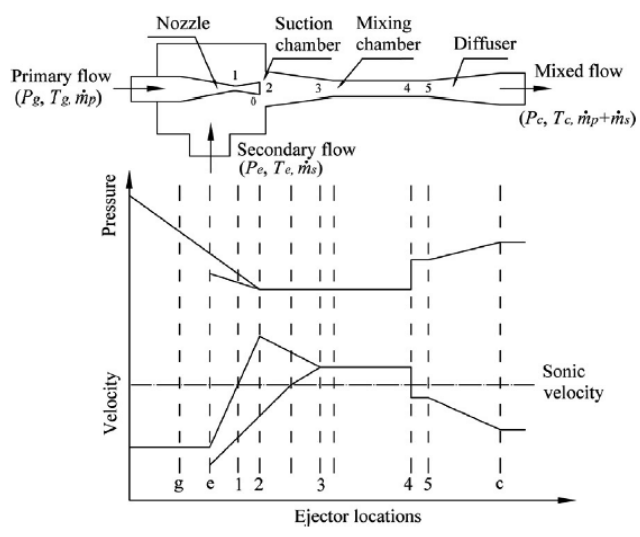

Fig. 2 Schematic view of an ejector and variations of pressure \& velocity along the ejector

Referring to Figure 2, the ejector parts and their working pro-cesses can generally be explained as follows:

1) Nozzle: the primary flow enters into the convergent-divergent nozzle and undergoes processes of pressure reduction and velocity increase in the convergent part. The velocity reaches sonic speed at nozzle throat (1). At the divergent part, the velocity increases up to supersonic as the pressure decreases following the energy conservation law. A low pressure region is created at the nozzle exit (2).

2) Suction chamber: a pressure difference between the suction chamber and the secondary flow is established, inducing the secondary flow into the ejector $(0)$.

3) Mixing chamber: the primary flow fans out without mixing with the secondary flow at the very first beginning, resulting in a converging duct which acts as converging nozzle for the secondary flow. At some cross-section along this duct, the speed of the secondary flow rises to sonic value. After that, the two flows start to mix and end with the same velocity and pressure (3). Due to the supersonic flow in the mixing chamber, a shock is formed at some place (4) which causes a sudden compression and a quick drop in the velocity from supersonic to subsonic.

4) Diffuser: the mixed flow (5) passes through the diffuser and converts kinetic energy into pressure energy, resulting in further pressure increase and velocity decrease. Finally, it fans out at the back pressure.

\subsection{Chocking phenomenon and shock}

Choked flow is a phenomenon that occurs under specific conditions when a flow at a certain pressure passes through a restriction into a lower pressure and the velocity reaches to sound speed, in which mass flow rate of the fluid becomes irrelevant to the downstream pressure. In other word, the mass flow of a choked flow is constant even the downstream pressure 
further decreases. Practically, two choking phenomena exist in the ejector. One occurs in the primary flow through nozzle, the second choking results from the acceleration of the secondary flow from a stagnant state at the suction port to a supersonic flow along the duct in the mixing chamber. The appearance of the second choking phenomena directly depends on the ejector back pressure $\mathrm{P}_{\mathrm{b}}$. If $\mathrm{P}_{\mathrm{b}}$ is below the critical back pressure $\mathrm{P}_{\mathrm{bn}}$, the primary flow and the secondary flow are both choked, causing constant mass flow rate.

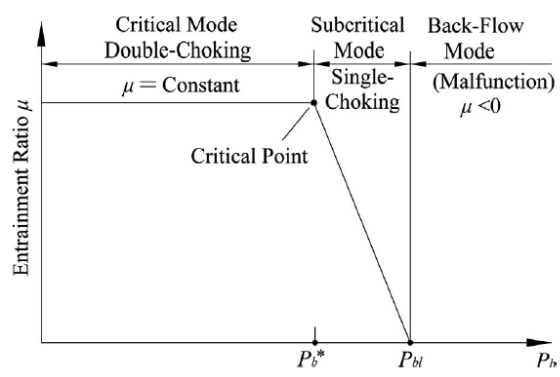

Fig. 3. Operational modes for a fixed-geometry ejector

\section{Ejector Expansion Refrigeration System}

A layout diagram of the two-phase ejector-expansion refrigeration cycle and the corresponding $\mathrm{p}$-h diagram are shown in Figure 4. The high-pressure liquid at outlet from the condenser is expanded through the motive nozzle of the ejector. This expansion of the high-pressure liquid is then applied to entrain and raises the vapour pressure at the outlet of the evaporator. Then mixing occurred between the two streams in the mixing chamber. Next, the mixed fluid enters a diffusion nozzle, where the fluid are further decelerated and compressed to a pressure higher than the initial pressure of the suction stream. The twophase fluid at the outlet of the ejector is sent to the liquid-vapour separator, where the vapour enters the compressor and ultimately becomes the motive stream, while the liquid returns to the evaporator through a throttle valve and ultimately becomes the suction stream. Compared with the basic refrigeration cycle, the compression work required for the cycle is decreased owing to the higher compressor inlet pressure. Besides, an increase in evaporator capacity can be attained owing to the lower evaporator inlet enthalpy compared to an isenthalpic expansion.
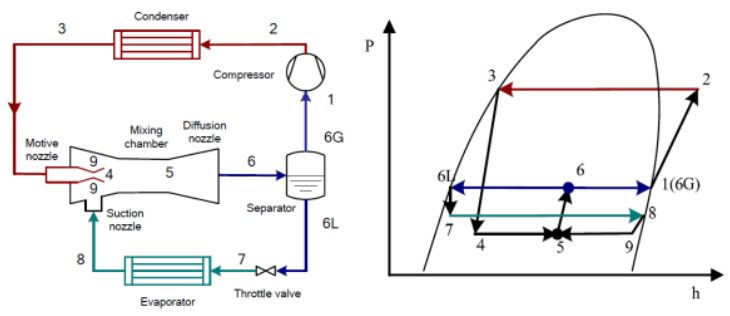

Fig.4 Schematic and P-h diagram of the ejector expansion refrigeration cycle

\section{Condensor outlet split Ejector system}

In the condenser outlet split ejector system proposed by Oshitani et al., the liquid at the outlet of the condenser is split into two separate streams; one stream is sent to the motive nozzle of the ejector, and the other is isenthalpically throttled and sent to an evaporator. The refrigerant that was throttled is vaporized in an evaporator and sent to the suction nozzle of the ejector. The two streams then mix in the ejector and enter a second evaporator, where they are vaporized before returning to the compressor and condenser. Because the flow is split at the outlet of the condenser in this cycle, the cycle will be referred to as the COS (condenser outlet split) ejector cycle.

Because of the pressure lift provided by the ejector, the evaporator at the outlet of the ejector will have a higher evaporation temperature than the evaporator before the ejector suction nozzle. Thus, the two evaporators will be referred to as the high and the low temperature evaporators, shown in Figure 5. Note that the COS ejector cycle can be constructed such that the total surface area of the evaporators is the same as the surface area of the evaporator in an expansion valve cycle; the additional evaporation temperature in the COS ejector cycle does not necessarily increase overall evaporator size.

Oshitani et al. described two earlier attempts to use the COS ejector cycle in real automotive applications. The latest commercialization of the COS ejector cycle has been for use in passenger cars to provide cabin airconditioning (Brodie et al.). In this system, both evaporators were used to cool a single air stream; the intent was to use the two different evaporation temperatures to better match the temperature glide of the air.

(a)

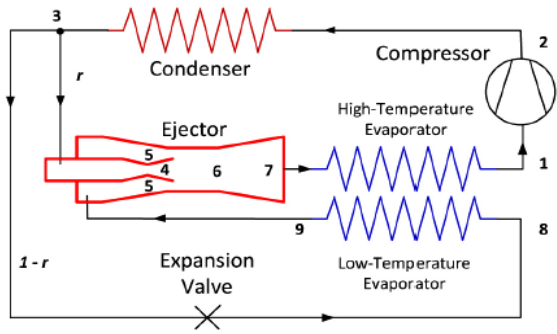

(b)

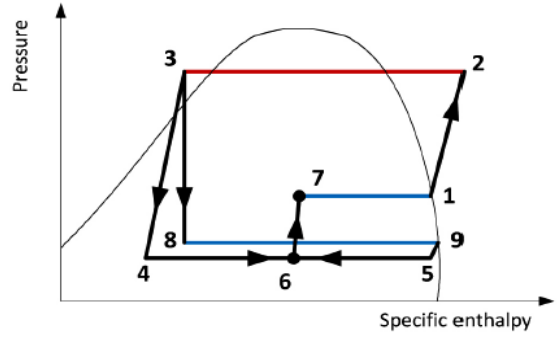

Fig.5 Schematic and P-h diagram of the condenser outlet split ejector system

Brodie et al. observed COP improvements of 10 to 25 $\%$ in this application with an unspecified working fluid. 
In the automotive system described by Brodie et al., the ejector and the high- and low-temperature evaporators were actually integrated into a single evaporator manifold, which was the same size as a single evaporator without an ejector. Thus, the additional evaporator and the ejector in the COS ejector cycle did not significantly increase the size of the system.

\section{Ejector Component Performance}

The performance of the ejector is commonly measured in terms of the suction pressure ratio (п) and mass entrainment ratio $(\Phi)$, shown in equations (1) and (2), respectively. The suction pressure ratio is a direct measure of the pressure increase to the suction stream that the ejector provides. The mass entrainment ratio is a measure of the ejectors ability to entrain mass through the suction nozzle. Note that it is desirable to obtain both high pressure ratio and high entrainment ratio. However, there is generally a tradeoff between pressure increase and mass entrainment.

$\Pi=\frac{P_{\text {diff }, \text { out }}}{P_{\text {sn,in }}}$

$\Phi=\frac{\dot{\mathrm{m}}_{\mathrm{sn}}}{\dot{\mathrm{m}}_{\mathrm{mn}}}$

Where $P_{\text {diff,out }}$ is pressure at diffuser outlet.

$\mathrm{P}_{\mathrm{sn}, \text { in }}$ is pressure at suction inlet of ejector.

$\dot{\mathrm{m}}_{\mathrm{sn}}$ is mass flow rate at suction nozzle.

$\dot{\mathrm{m}}_{\mathrm{mn}}$ is mass flow rate at motive nozzle inlet.

\section{Conclusions}

Various studies in ejector systems that have been carried out over the past decade involved system modeling, design fundamentals, refrigerants selection and system optimization. The research and development was broadly based and productive, concentrating on performance enhancement methodology and feasibility of combining Ejector refrigeration system (ERS) with other systems. This paper presents not only a basic background and principles for ejector design, but also the recent improvement in ejector refrigeration technologies. The following conclusions can be drawn from the reviewed works that have been carried out in ejector refrigeration system:

1) Attempts have been made on the investigations of proper mathematical models which may help to optimize design parameters. Taking into consideration of friction losses and irreversibilites, some researchers have carried out computer simulations on the improvement of constant-area model and constant pressure model. A number of researchers have concentrated on the studies of two-phase flow and specific characteristics of working fluids. Computational Fluid Dynamics has been identified as a suitable tool for the turbulence models of the mixing process which can better simulate and optimize the geometry of ejector. Although these simulated results were claimed to become more accurate than others, very few of them were experimentally verified and approved.

2) The ejector refrigeration systems suffer from relatively low COP improvement still there are number of studies which have focused on system performance enhancement. Operation of ERS without a pump has been declared to considerably reduce the mechanical energy consumption. In contrast, ERS with an additional pump could help to increase the entrainment ratio and COP. In order to cope with variations of working conditions, multicomponents ERS are parametrically studied.

3) There are remarkable COP improvements from combined ejector and refrigeration systems which are reported by many research groups. However, most of those studied are limited to numerical analysis, with few experimental results available.

\section{References}

Rounak Sahni,(2015) Ejector Expansion Refrigeration Systems, International Journal of Engineering And Science , Vol.5, Issue 2 , PP 25-29

Nehdi, E.; Kairouani, L.; Bouzaina, M.,(2007) Performance analysis of the vapour compression cycle using ejector as an expander. International Journal of Energy Recourses, 31, 364-375.

Bilir, N.; Ersoy, H.K. ,(2009)Performance improvement of the vapour compression refrigeration cycle by two-phase constant area ejector. International Journal of Energy Recourses, 33, 469-480.

Disawas, S.; Wongwises S., (2004), Experimental investigation on the performance of the refrigeration cycle using a two-phase ejector as an expansion device. International Journal of Refrigeration, 27, 587-594.

Pottker, G.; Hrnjak, P.,(2015) Ejector in R410A vapor compression systems with experimental quantification of two major mechanisms of performance improvement: Work recovery and liquid feeding. International Journal of Refrigeration, 50, 184-192.

Lawrence, N.; Elbel, S., (2014), Experimental investigation of a two-phase ejector cycle suitable for use with lowpressure refrigerants R134a and R1234yf, International Journal of Refrigeration, 38, 310-322.

K. Sumeru, H.Nasution, F.N.Ani,(2012), A review on twophase ejector as an expansion device in vapour compression refrigeration cycle. Renewable and Sustainable Energy Reviews 16 (2012) 4927-4937

Zhenying Zhang, Lirui Tong, Li Chang, Yanhua Chen and Xingguo Wang, (2015), Energetic and Exergetic Analysis of an Ejector-Expansion Refrigeration Cycle Using the Working Fluid R32.Entropy ,17, 4744-4761.

Jichao Hu, Junye Shi, Yuanyuan Liang, Zijiang Yang, Jiangping Chen,(2014), Numerical and experimental investigation on nozzle parameters for R410A ejector air conditioning system , International Journal of Refrigeration 40 , 338-346.

A.A. Kornhauser,(1990), The use of an ejector as a refrigerant expander, in: Proceeding of the USN/IIR-Purdue Refrigeration Conference, West Lafayette, IN, USA, pp. 1019. 
K. Sumeru, H. Nasution, F.N. Ani,(2013), Numerical study of ejector as an expansion device in split-type air conditioner, Applied Mechanics and Materials 388, 101-105.

P. Chaiwongsa, S. Wongwises,(2007), Effect of throat diameters of the ejector on the performance of the refrigeration cycle using a two-phase ejector as an expansion device, International Journal of Refrigeration 30 ,601-608.

C. Lucas, J. Koehler,(2012) Experimental investigation of the COP improvement of a refrigeration cycle by use of an ejector, International Journal of Refrigeration 35 15951603.
S. Elbel,(2011), Historical and present developments of ejector refrigeration systems with emphasis on transcritical carbon dioxide air-conditioning applications, International Journal of Refrigeration 34 1545-1561.

Oshitani, H., Yamanaka, Y., Takeuchi, H., Kusano, K.,Ikegami, M., Takano, Y., Ishizaka, N., and Sugiura, T.,(2005),Vapor Compression Cycle Having Ejector, U.S. Patent Application Publication US2005/0268644 A1, 2005.

Brodie, B., Takano, Y., and Gocho, M.,(2012) Evaporator with Integrated Ejector for Automotive Cabin Cooling, SAE Technical Paper 2012-01-1048, doi: 10.4271/2012-011048. 